\title{
Follow-up of renal function in treated and untreated older patients with isolated systolic hypertension
} Sofia M. Voyakia,b, Jan A. Staessen ${ }^{a}$, Lutgarde Thijs ${ }^{a}$, Ji G. Wang ${ }^{a}$, Aris D. Efstratopoulos ${ }^{b}$, Willem H. Birkenhäger ${ }^{c}$, Peter W. de Leeuw ${ }^{d}$, Gastone Leonetti ${ }^{\mathrm{e}}$, Choudomir Nachev ${ }^{\mathrm{f}}$, José L. Rodiciog, Jaakko Tuomilehto ${ }^{\mathrm{h}}$, Robert Fagard ${ }^{\mathrm{a}}$, for the Systolic Hypertension in Europe (Syst-Eur) Trial Investigators

Background In the outcome trials that provided information on renal function in older hypertensive patients, diuretics and $\beta$-blockers were mostly used as first-line drugs. The long-term renal effects of calciumchannel blockers remain unclear.

Objective To compare the changes in renal function in 2258 treated and 2148 untreated patients with isolated systolic hypertension, of whom $\mathbf{4 5 5}$ had diabetes mellitus and 390 had proteinuria.

Methods We performed a post-hoc analysis of the doubleblind placebo-controlled Systolic Hypertension in Europe (Syst-Eur) Trial. Active treatment was initiated with nitrendipine (10-40 mg/day) with the possible addition of enalapril (5-20 mg/day), hydrochlorothiazide (12.5$25 \mathrm{mg} /$ day), or both, titrated or combined to reduce the sitting systolic blood pressure by at least $20 \mathrm{mmHg}$, to less than $150 \mathrm{mmHg}$. The main outcome measures were serum creatinine concentration and creatinine clearance calculated by the formula of Cockroft and Gault.

Results Serum creatinine concentration at the time when participants were randomly allocated to study groups was less than $176.8 \mu \mathrm{mol} / \mathrm{l}(2.0 \mathrm{mg} / \mathrm{dl})$, averaging $88 \mu \mathrm{mol} / \mathrm{l}$. At the time of the last serum creatinine measurement, the blood pressure difference $(P<0.001)$ between the two groups was $11.6 / 4.1 \mathrm{mmHg}$. In the intention-to-treat analysis (11427 patient-years), serum creatinine and the calculated creatinine clearance were not influenced by active treatment. However, in the patients assigned randomly to receive active treatment, the incidence of mild renal dysfunction (serum creatinine at least $176.8 \mathrm{mmol} / \mathrm{l}$ ) decreased by $64 \%(P=0.04)$ and that of proteinuria by 33\% $(P=0.03)$. Active treatment reduced the risk of proteinuria more in diabetic than in non-diabetic patients: by $71 \%$, compared with $20 \%(P=0.04)$. In non-proteinuric patients, active treatment did not influence serum creatinine, whereas in patients with proteinuria at entry to the study, serum creatinine decreased on active treatment $(P<0.001)$. Furthermore, in on-randomized treatment comparison stratified for risk at baseline, serum creatinine concentration did not change $(P=0.98)$ in patients continuing to receive monotherapy with nitrendipine, whereas it increased by $6.73 \mathrm{mmol} / \mathrm{I}(P<0.001)$ in patients who received hydrochlorothiazide alone or in combination with other study medication $(P<0.001$ for difference in trends).

Conclusions In older patients with isolated systolic hypertension, antihypertensive treatment starting with the dihydropyridine calcium-channel blocker, nitrendipine, did not decrease blood pressure at the expense of renal function and prevented the development of proteinuria, especially in diabetic patients. $J$ Hypertens 19:511-519 @ 2001 Lippincott Williams \& Wilkins.

Journal of Hypertension 2001, 19:511-519

Keywords: calcium-channel blockade, diabetes mellitus, isolated systolic hypertension, proteinuria, renal function, serum creatinine

${ }^{a}$ Departement voor Moleculair en Cardiovasculair Onderzoek, Katholieke Universiteit Leuven, Leuven, Belgium, ${ }^{b}$ Department of Internal Medicine and Hypertension Unit, General Hospital of Athens, Greece, 'Erasmus University, Rotterdam, The Netherlands, dDepartement Inwendige Geneeskunde, Rijksuniversiteit Maastricht, Maastricht, the Netherlands, ${ }^{\mathrm{e}}$ Istituto Auxologico Italiano and Centro di Fisiologia Clinica e Ipertensione, Ospedale Maggiore, Universitá di Milano, Italy, ' $D$ epartment of Internal Medicine, Alexandrov's University Hospital, Sofia, Bulgaria, 9Unidad de Hypertensión, Hospital 12 de Octubre, Madrid, Spain and hepartment of Epidemiology and Health Promotion, National Public Health Institute, Helsinki, Finland. (A complete list of the Syst-Eur Investigators appears in reference [14].)

The trial was sponsored by Bayer AG (Wuppertal, Germany). The National Fund for Scientific Research (Brussels, Belgium) provided additional support. Study medication was donated by Bayer AG and Merck Sharpe and Dohme Inc, West Point, Philadelphia, USA.

Correspondence and requests for reprints to Jan A. Staessen, MD, PhD, Study Coordinating Office, Laboratory of Hypertension, Department of Molecular and Cardiovascular Research, University of Leuven, Campus Gasthuisberg,

Herestraat 49, $\beta$-3000 Leuven, Belgium.

Tel: +32 16 347104; fax; +32 16347106 ; e-mail:

jan.staessen@med.kuleuven.ac.be

Received 13 September 2000 Revised 16 November 2000 Accepted 17 November 2000

disease, hypertension is the primary cause [1]. With advancing age, renal function declines [1,2] and the 
prevalence of isolated systolic hypertension increases, exceeding $20 \%$ in octagenarians [3]. Nevertheless, among the outcome trials in elderly hypertensive patients, only five [4-8] provided published information on the changes in renal function in treated or untreated patients. Drug treatment in four [4-6,8] of these five reports consisted of diuretics, $\beta$-blockers or both classes of drug. Few trials studied the possible renoprotective effects of calcium-channel blockers in hypertension [7,9-12]. The number of patients enrolled in most of these studies was small $[9,10]$. In only one outcome trial with information on renal function [6], systolic hypertension constituted the main selection criterion.

In the Systolic Hypertension in Europe (Syst-Eur) Trial [13-15], patients were selected because their untreated systolic blood pressure was $160 \mathrm{mmHg}$ or greater, with diastolic blood pressure less than $95 \mathrm{mmHg}$. In this double-blind, placebo-controlled trial, active treatment was initiated with the dihydropyridine calcium-channel blocker, nitrendipine [16], with the possible addition of enalapril or hydrochlorothiazide or both drugs $[13,14]$. At the time of random allocation to groups, approximately $10 \%$ of the patients had diabetes mellitus [15]. In view of the uncertainty with regard to the renoprotective effects of antihypertensive treatment in elderly patients [17], in particular those with isolated systolic hypertension or with diabetes mellitus [12] or those treated with dihydropyridines [10-12,18], we studied the changes in renal function in untreated and treated patients participating in the Syst-Eur trial. In the analysis, we accounted for the presence of diabetes mellitus or proteinuria at entry.

\section{Methods}

The procedure of the Syst-Eur trial was approved by the Ethics Committees of the University of Leuven and the participating centres. The inclusion and exclusion criteria, the definition of endpoints and the procedures for recruitment and random allocation to groups have been published elsewhere [13]. Eligible patients were aged 60 years or more. On conventional measurement, they had a sitting systolic blood pressure of 160 $219 \mathrm{mmHg}$, with diastolic blood pressure less than $95 \mathrm{mmHg}$. Patients with a serum creatinine concentration of $176.8 \mu \mathrm{mol} / \mathrm{l}(2.0 \mathrm{mg} / \mathrm{dl})$ or greater were excluded from the study [13]. Eligible patients were allocated randomly to groups to receive double-blind treatment with active medication or placebo. The study medications were stepwise titrated and combined to reduce the sitting systolic blood pressure, by $20 \mathrm{mmHg}$ or more, to less than $150 \mathrm{mmHg}$ [13]. Active treatment was initiated with nitrendipine $(10-40 \mathrm{mg} /$ day) [16]. If necessary, the dihydropyridine was combined with or replaced by enalapril $(5-20 \mathrm{mg} / \mathrm{day})$, hydrochlorothiazide $(12.5-25 \mathrm{mg} /$ day), or both drugs. In the control group, identical placebos were used in the same way.
At entry to the study and at yearly intervals thereafter, the serum creatinine concentration was measured and fresh urine samples were examined for proteinuria $(>300 \mathrm{mg} / \mathrm{l})$, using a semiquantitative dipstick method. In patients proceeding to receive enapril or matching placebo, serum creatinine measurements were repeated at 3-month intervals for 1 year. We used published formulae to compute body surface area [19], creatinine clearance [20] and lean body weight [21]. Diabetes at entry was defined, according to the criteria of the World Health Organization [22], as a history of diabetes mellitus, treatment with anti-diabetic drugs, or a fasting or postprandial blood glucose concentration of at least $7.8 \mathrm{mmol} / \mathrm{l}$ or $11.1 \mathrm{mmol} / \mathrm{l}$, respectively. The diagnosis of incident proteinuria required the absence of this disorder at baseline and the presence of a positive test on at least two follow-up visits. Mild or severe renal insufficiency were diagnosed if, during follow-up, serum creatinine attained concentrations of $176.8 \mu \mathrm{mol} / \mathrm{l}$ $(2.0 \mathrm{mg} / \mathrm{dl})$ or $353.6 \mu \mathrm{mol} / \mathrm{l}(4.0 \mathrm{mg} / \mathrm{dl})$, respectively. The diagnosis of mild renal dysfunction also required that the serum creatinine concentration remained greater than $176.8 \mu \mathrm{mol} / \mathrm{l}$ on at least two occasions, or that it had doubled compared with the concentration at entry. Of 4695 patients allocated randomly to groups, 4406 were elegible for inclusion in the analysis as serum creatinine concentration had been measured at baseline and at least once during follow-up.

We used SAS software, version 6.12 (SAS Institute Inc., Cary, North Carolina, USA) for database management and statistical analysis and determined significance from two-sided tests. Net differences in measurements obtained during follow-up were calculated by subtracting the mean change from baseline in the placebo group from the corresponding mean change in the active-treatment group. The significance of mean unadjusted differences was determined from the normal $z$ distribution. We contrasted proportions by $\chi^{2}$ analysis and survival curves using Kaplan-Meier survival function estimates and the log-rank statistic. We tested differences in blood pressure, serum creatinine concentration and calculated creatinine clearance by analysis of covariance or repeated measures analysis of variance (cohorts with 2 years and up to 5 years of follow-up) with adjustment for the baseline values and possible confounders $[14,15]$. We calculated relative hazard rates by multiple Cox regression adjusted for treatment group and other significant covariates [14]. We used multiple regression analysis and the single model approach [23] to compare regression coefficients.

\section{Results \\ Patients characteristics at the time of random allocation to groups}

At random allocation to groups, the patients in the placebo $(n=2148)$ and active-treatment $(n=2258)$ 
groups had similar characteristics (Table 1). The 4406 patients had a mean $( \pm \mathrm{SD})$ age of $70.0 \pm 6.6$ years. The serum creatinine concentration was $88.0 \pm 18.7$ $\mu \mathrm{mol} / \mathrm{l}$ and the calculated [20] creatinine clearance was $64.4 \pm 17.1 \mathrm{ml} / \mathrm{min}$ per $1.73 \mathrm{~m}^{2}$. Body mass index averaged $26.5 \pm 3.2 \mathrm{~kg} / \mathrm{m}^{2}$ in 1459 men and $27.4 \pm 4.4 \mathrm{~kg} /$ $\mathrm{m}^{2}$ in 2974 women; the corresponding values of lean body weight were $59.8 \pm 4.7 \mathrm{~kg}$ and $40.3 \pm 3.1 \mathrm{~kg}$, respectively. Previous cardiovascular complications were present in 1311 patients (29.8\%), of whom 584 had a Sokolow-Lyon voltage index [24] compatible with left ventricular hypertrophy.

\section{Treatment and blood pressure during follow-up}

The median follow-up in the 4406 patients was 2.0 years, ranging from 1 to 97 months. The number of patient-years in the placebo and active-treatment groups amounted to 5566 and 5861, respectively.

At the time of the last serum creatinine measurement (Table 2), 1533 patients of the placebo group and 1795 of the active-treatment group were still receiving double-blind treatment (71.4 compared with 79.5\%; $P<0.001$ ), whereas 615 and 463 patients were in open follow-up (28.6 compared with 20.5\%; $P<0.001$ ). Of the actively treated patients in the double-blind phase of the trial, $1571(87.5 \%)$ were taking nitrendipine (mean daily dose $28.5 \mathrm{mg}$ ) either alone $(n=1078)$ or in combination with other study medication $(n=493)$; $614(34.2 \%)$ patients were taking enalapril $(13.9 \mathrm{mg})$ and $273(15.2 \%)$ hydrochlorothiazide $(21.5 \mathrm{mg})$. For the matching placebos in the control group, these numbers were 1415 (92.3\%), 868 (56.6\%) and 476 (31.3\%), respectively.

In the intention-to-treat analysis with adjustment for baseline and possible confounders, the blood pressure differences between the two treatment groups at the last serum creatinine measurement averaged 11.6 $\mathrm{mmHg}$ (95\% confidence interval (CI) $10.7-12.4 \mathrm{mmHg}$ ) systolic and $4.1 \mathrm{mmHg}$ (CI $3.6-4.5 \mathrm{mmHg}$ ) diastolic. Repeated measures analysis of variance in the cohorts with a follow-up ranging from 2 to 5 years showed that the diastolic blood pressure differences between the two treatment groups tended to increase, from $3.7 \mathrm{mmHg}$ (CI $3.2-4.1 \mathrm{mmHg}$ ) in the 2-year cohort to $5.2 \mathrm{mmHg}$ (CI $4.2-6.1 \mathrm{mmHg}$ ) in the 5 year cohort. The corresponding differences for systolic blood pressure ranged from $9.9 \mathrm{mmHg}$ (CI $9.0-10.8 \mathrm{mmHg}$ ) in the 2-year cohort to $11.2 \mathrm{mmHg}$ (CI $9.4-13.0 \mathrm{mmHg}$ ) in the 5 -year cohort.

\section{Intention-to-treat analysis of renal function}

In all available patients and in the 1-year to 5-year cohorts, active treatment did not significantly influence the unadjusted (Fig. 1) or adjusted (Table 3) serum creatinine concentrations or the adjusted creatinine clearance (Table 3). Over time, the calculated creatinine clearance declined slightly but significantly. In the 2-year and 5-year cohorts, the decreases in the calculated creatinine clearance averaged $1.50 \mathrm{ml} / \mathrm{min}$ per $1.73 \mathrm{~m}^{2} \quad\left(95 \%\right.$ CI $1.11-1.89 \mathrm{ml} / \mathrm{min}$ per $1.73 \mathrm{~m}^{2}$;

Table 1 Baseline characteristics of patients according to randomization group

\begin{tabular}{lcc}
\hline & Placebo & Active treatment \\
\hline Number of patients & 2148 & 2258 \\
Clinical characteristics & & \\
Age (years) & $70.0 \pm 6.5$ & $70.0 \pm 6.6$ \\
Women & $1426(66.4)$ & $1521(67.4)$ \\
Systolic blood pressure $(\mathrm{mmHg})$ & $174.0 \pm 10.1$ & $173.8 \pm 9.9$ \\
Diastolic blood pressure $(\mathrm{mmHg})$ & $85.5 \pm 5.8$ & $85.5 \pm 5.8$ \\
Heart rate $($ beats $/$ min) & $72.9 \pm 8.1$ & $73.2 \pm 7.8$ \\
Body mass index $\left(\mathrm{kg} / \mathrm{m}^{2}\right)$ & $26.3 \pm 3.1$ & $26.6 \pm 3.3$ \\
$\quad$ Men & $27.5 \pm 4.3$ & $27.3 \pm 4.5$ \\
Women & & \\
History & $1011(47.1)$ & $1044(46.2)$ \\
Previous antihypertensive treatment & $644(30.0)$ & $667(29.5)$ \\
Cardiovascular complications & $146(6.8)$ & $161(7.1)$ \\
Current smokers & $245(11.4)$ & $240(10.6)$ \\
Using $\geqslant 1$ unit of alcohol per day & $224(10.4)$ & $231(10.2)$ \\
Diabetes mellitus & $88.3 \pm 18.7$ & $87.8 \pm 18.7$ \\
Renal function & $64.1 \pm 15.9$ & $64.7 \pm 18.2$ \\
Serum creatinine $(\mu m o l / l)$ & & \\
Calculated creatinine & $1940(90.3)$ & $199(8.8)$ \\
$\quad$ clearance $\left(\mathrm{ml} / \mathrm{min}\right.$ per $\left.1.73 \mathrm{~m}^{2}\right)$ & $191(8.9)$ & $16(0.7)$ \\
Proteinuria & $17(0.8)$ & \\
Absent & &
\end{tabular}

Values are means $\pm \mathrm{SD}$ or number (\%). Creatinine clearance was calculated according to the formula of Cockcroft and Gault [20]. Patients of the placebo and active-treatment groups had similar characteristics. 
Table 2 Treatment status in the active-treatment group at the last measurement of serum creatinine

\begin{tabular}{|c|c|c|c|c|c|}
\hline & \multirow[b]{2}{*}{ All patients } & \multicolumn{2}{|c|}{ Diabetes mellitus at entry } & \multicolumn{2}{|c|}{ Proteinuria at entry } \\
\hline & & Absent & Present & Absent & Present \\
\hline Randomized to active treatment & 2258 & 2027 & 231 & 2043 & 199 \\
\hline In double-blind follow-up & 1795 & 1611 & 184 & 1621 & 164 \\
\hline Monotherapy & $1233(68.7)$ & $1106(68.7)$ & $127(69.0)$ & $1122(69.2)$ & $106(64.6)$ \\
\hline Nitrendipine & $1078(60.1)$ & $966(60.0)$ & $112(60.9)$ & 977 (60.3) & $97(59.2)$ \\
\hline Enalapril & $103(5.7)$ & $90(5.6)$ & $13(7.1)$ & $96(5.9)$ & $6(3.7)$ \\
\hline $\mathrm{HCT}$ & $52(2.9)$ & $50(3.1)$ & $2(1.1)$ & $49(3.0)$ & $3(1.8)$ \\
\hline Combination therapy & $552(30.7)$ & $495(30.7)$ & $57(31.0)$ & $489(30.2)$ & $58(35.4)$ \\
\hline Nitrendipine + enalapril & $331(18.4)$ & 295 (18.3) & $36(19.6)$ & $301(18.6)$ & $25(15.2)$ \\
\hline Nitrendipine + HCT & $41(2.3)$ & $39(2.4)$ & $2(1.1)$ & $37(2.3)$ & $4(2.4)$ \\
\hline Enalapril + HCT & 59 (3.3) & $56(3.5)$ & $3(1.6)$ & $53(3.3)$ & $6(3.7)$ \\
\hline Nitrendipine + enalapril + HCT & $121(6.7)$ & $105(6.5)$ & $16(8.7)$ & $98(6.0)$ & $23(14.0)^{* * *}$ \\
\hline Unspecified or no study drugs & $10(0.6)$ & $10(0.6)$ & $0(0.0)$ & $10(0.6)$ & $0(0.0)$ \\
\hline Number in open follow-up & 463 & 416 & 47 & 422 & 35 \\
\hline Antihypertensive drugs & $155(33.5)$ & $142(34.1)$ & $13(27.7)$ & $141(33.4)$ & $11(31.4)$ \\
\hline No antihypertensive drugs & $308(66.5)$ & $274(65.9)$ & $34(72.3)$ & $281(66.6)$ & $24(68.6)$ \\
\hline
\end{tabular}

Values are number or number (\%). HCT, hydrochlorothiazide. ${ }^{* * *} P<0.001$ for difference between non-proteinuric and proteinuric patients.

Fig. 1

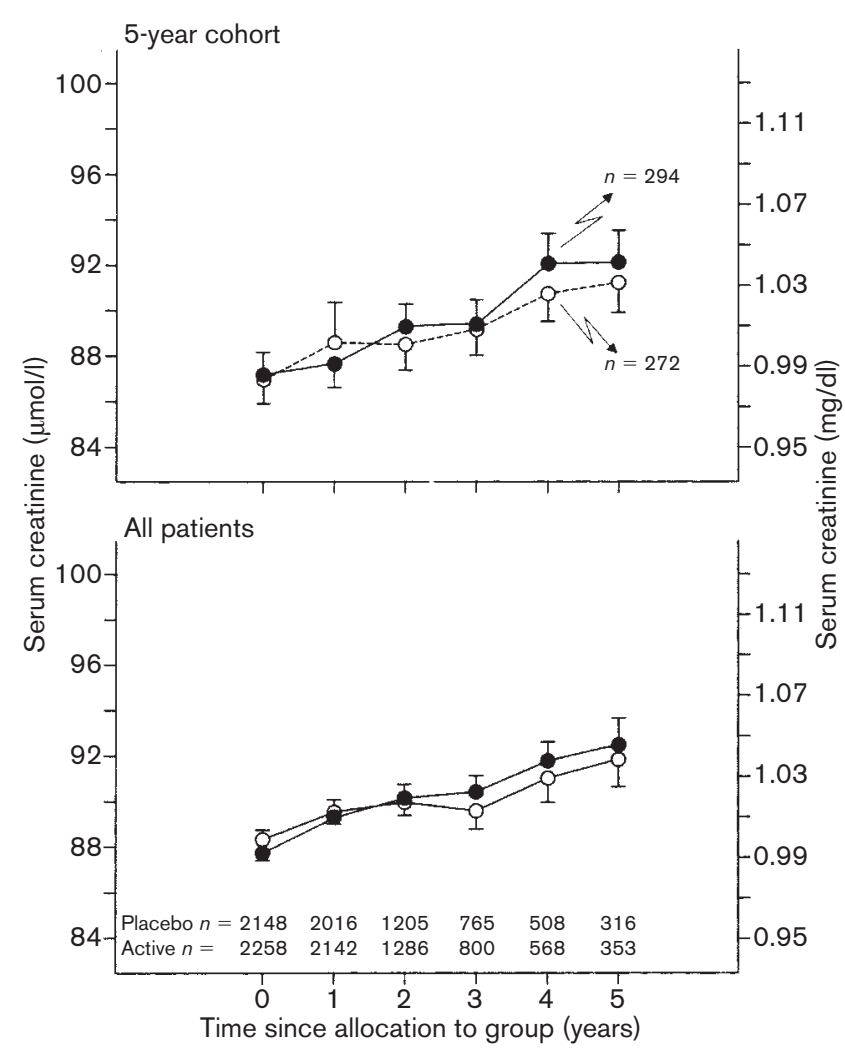

The unadjusted serum creatinine concentration in the 5-year cohort and in all available patients by treatment group and year of follow-up. $\bigcirc$, Placebo; $\bullet$, active treatment.

$P<0.001)$ and $5.97 \mathrm{ml} / \mathrm{min}$ per $1.73 \mathrm{~m}^{2}$ (CI 5.26 $6.68 \mathrm{ml} / \mathrm{min}$ per $\left.1.73 \mathrm{~m}^{2} ; \quad P<0.001\right)$, respectively. These changes in the calculated creatinine clearance were not accompanied by significant increases in serum creatinine (Table 3). Over the same follow-up periods, lean body weight decreased by $0.06 \mathrm{~kg}$ (CI $0.04-$ $0.08 \mathrm{~kg} ; \quad P<0.001)$ and $0.10 \mathrm{~kg} \quad(\mathrm{CI} \quad 0.04-0.15 \mathrm{~kg}$; $P=0.001)$. In the 2-year cohort, both before and after adjustment for confounders, an inverse correlation $(P=0.002)$ was apparent between the changes in systolic blood pressure and serum creatinine concentration, but these relationships were similar in patients allocated randomly to placebo and active treatment (adjusted slope (SE) -0.056 (0.032) compared with -0.087 (0.034) $\mu \mathrm{mol} / \mathrm{l}$ per $\mathrm{mmHg} ; P=0.50)$.

Mild renal dysfunction occurred in 13 patients in the placebo group and in five of the active-treatment group, one of whom was taking hydrochlorothiazide. Active treatment reduced the rate of dysfunction by $64 \%$ (CI $0-87 \% ; P=0.04)$ - from 2.6 to 0.9 events per 1000 patient-years. In Cox regression with adjustments for sex, age, systolic blood pressure at entry, previous cardiovascular complications and antihypertensive treatment, body mass index and smoking and alcohol intake at entry, the reduction was $64 \%$ (CI $0-84 \% ; P=0.05$ ). Furthermore, only one patient in the placebo group attained a serum creatinine concentration of $353.6 \mu \mathrm{mol} / \mathrm{l}$, and no patient died of renal failure.

The incidence of proteinuria by treatment group and year of follow-up is shown in Figure 2. The cumulative rates were 18.9 and 12.7 events per 1000 patient-years. Thus, in all patients, active treatment reduced the occurrence of proteinuria by $33 \%$ (CI $4-53 \% ; P=0.03$ ). In Cox regression with similar adjustments as before, the reduction was $34 \%$ (CI 5-54\%; $P=0.02$; Fig. 3).

\section{On-randomized treatment analysis of renal function}

In the on-randomized treatment analysis, the number of patient-years amounted to 3439 in the placebo group and to 4344 in the group receiving active treatment. At 


\begin{tabular}{|c|c|c|c|c|c|c|c|}
\hline & No. & Placebo* & $\begin{array}{c}\text { Active } \\
\text { treatment* }\end{array}$ & Mean difference $\dagger$ & Treatment & $\begin{array}{c}P \dagger \\
\text { Time }\end{array}$ & Interaction \\
\hline \multicolumn{8}{|c|}{ Serum creatinine concentration $(\mu \mathrm{mol} / \mathrm{l})$} \\
\hline All patients & 4406 & $90.5 \pm 0.4$ & $90.7 \pm 0.4$ & $0.19(-0.81$ to 1.19$)$ & 0.71 & & \\
\hline 1-year cohort & 4158 & $89.3 \pm 0.3$ & $89.5 \pm 0.3$ & $0.22(-0.71$ to 1.14$)$ & 0.66 & & \\
\hline 2-year cohort & 2421 & $89.6 \pm 0.4$ & $89.6 \pm 0.4$ & $0.07(-1.05$ to 1.18$)$ & 0.91 & 0.79 & 0.21 \\
\hline 3-year cohort & 1436 & $88.4 \pm 0.5$ & $89.3 \pm 0.5$ & $0.91(-0.45$ to 2.27$)$ & 0.19 & 0.15 & 0.42 \\
\hline 4-year cohort & 925 & $89.2 \pm 0.6$ & $89.7 \pm 0.6$ & $0.51(-1.10$ to 2.11$)$ & 0.54 & 0.60 & 0.66 \\
\hline 5-year cohort & 566 & $89.6 \pm 0.8$ & $90.2 \pm 0.7$ & $0.53(-1.54$ to 2.60$)$ & 0.62 & 0.41 & 0.44 \\
\hline \multicolumn{8}{|c|}{ Creatinine clearance rate $\left(\mathrm{ml} / \mathrm{min}\right.$ per $\left.1.73 \mathrm{~m}^{2}\right) \S$} \\
\hline All patients & 4406 & $60.2 \pm 0.3$ & $59.7 \pm 0.2$ & $-0.46(-1.15$ to 0.24$)$ & 0.22 & & \\
\hline 1-year cohort & 4158 & $62.4 \pm 0.3$ & $61.7 \pm 0.2$ & $-0.71(-1.40$ to -0.02$)$ & 0.04 & & \\
\hline 2-year cohort & 2421 & $61.3 \pm 0.3$ & $61.0 \pm 0.3$ & $-0.34(-1.09$ to 0.41$)$ & 0.38 & 0.04 & 0.70 \\
\hline 3-year cohort & 1436 & $60.2 \pm 0.3$ & $60.4 \pm 0.3$ & $-0.80(-1.72$ to 0.11$)$ & 0.09 & 0.75 & 0.53 \\
\hline 4-year cohort & 925 & $59.9 \pm 0.4$ & $59.6 \pm 0.4$ & $-0.34(-1.37$ to 0.69$)$ & 0.52 & 0.26 & 0.99 \\
\hline 5-year cohort & 566 & $59.1 \pm 0.5$ & $58.9 \pm 0.4$ & $-0.21(-1.47$ to 1.05$)$ & 0.74 & 0.002 & 0.99 \\
\hline
\end{tabular}

Values are number, mean \pm SEM, or mean (95\% confidence interval). * Least square means adjusted for baseline value and various characteristics at entry: previous cardiovascular complications, diabetes mellitus, smoking and alcohol intake. The serum creatinine concentration was also adjusted for sex, age and body mass index. $\uparrow$ Active treatment minus placebo. $\$ P$ values are given for active compared with placebo treatment, time since random allocation to groups and the treatment-by-time interaction. $\S$ Creatinine clearance was calculated using the formula of Cockroft and Gault [20] and was standardized to a body surface area of 1.73 m ${ }^{2}$. The $P$ values for time and the time-by-treatment interactions did not materially change if, in Cockroft and Gault's formula [20], the actual age at each time point was substituted by age at baseline

Fig. 2

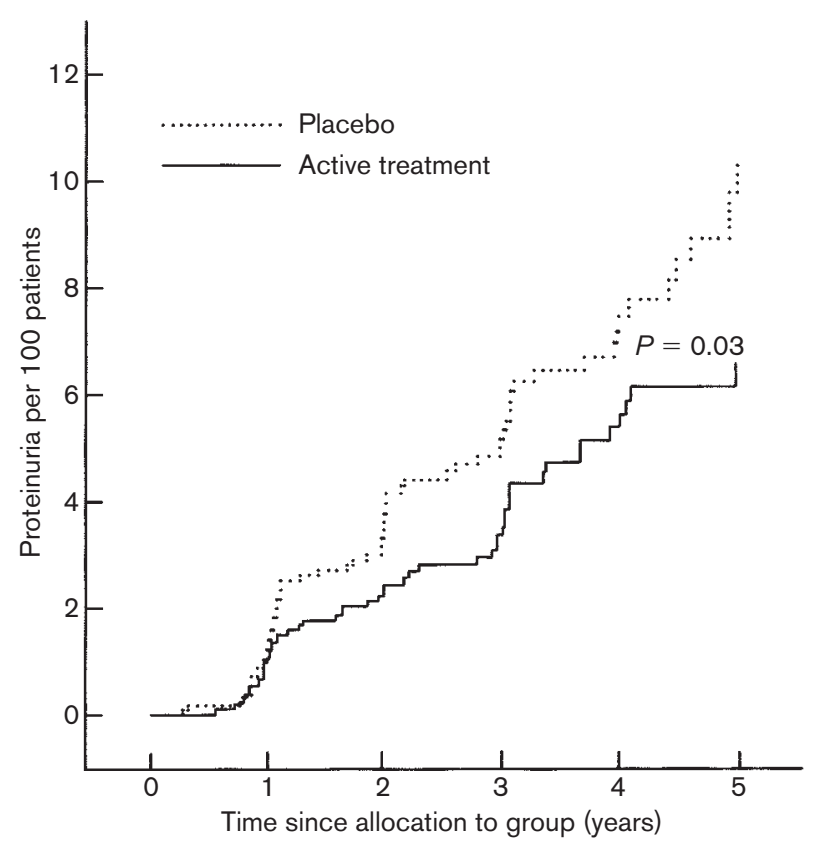

Incidence of proteinuria by treatment group and year of follow-up. The curves are Kaplan-Meier estimates, in which the denominator is the number of patients available for analysis at each time point. The cumulative rates in patients allocated randomly to receive placebo and active treatment were 18.9 and 12.7 events per 1000 patient-years, respectively $(P<0.03)$.

the last serum creatinine measurement, 1078 of 1795 actively treated patients $(60.1 \%)$ continued to receive monotherapy with nitrendipine, and 273 (15.2\%) were receiving hydrochlorothiazide alone or in combination with other study medication. These patients were
Fig. 3

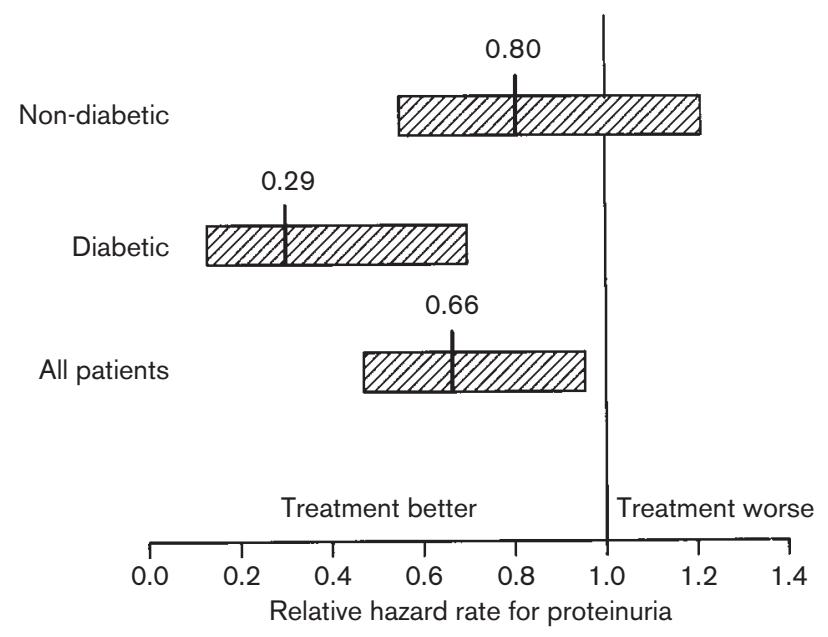

Influence of active treatment on the risk of proteinuria in all patients and in patients with or without diabetes at the time of random allocation to groups. The relative hazard rates were adjusted for various characteristics at entry: sex, age, systolic blood pressure, previous cardiovascular complications and antihypertensive treatment, body mass index, smoking and alcohol intake. A significant treatment-bydiabetes interaction $(P<0.04)$ indicated that the prevention of proteinuria was more pronounced in diabetic patients.

matched by sex, age (60-75 years, and older than 75 years), previous cardiovascular complications and systolic blood pressure at entry to the study (within $8 \mathrm{mmHg}$ ), with an equal number of patients drawn from the entire placebo group.

At the time of the last serum creatinine measurement, the systolic and diastolic blood pressure differences 
between patients receiving monotherapy with nitrendipine and the matched placebo group were $13.2 \mathrm{mmHg}$ (CI $\quad 11.9-14.4 \mathrm{mmHg}$ ) and $4.5 \mathrm{mmHg}$ (CI $3.8-$ $5.2 \mathrm{mmHg}$ ). In the patients receiving treatment with hydrochlorothiazide, these blood pressure differences were $11.0 \mathrm{mmHg}$ (CI $8.2-13.8 \mathrm{mmHg}$ ) and $3.3 \mathrm{mmHg}$ (CI $1.8-4.8 \mathrm{mmHg}$ ), respectively. With similar adjustments applied as in Table 3 , in the patients who continued to receive monotherapy with nitrendipine, serum creatinine did not change $(-0.015 \mu \mathrm{mol} / \mathrm{l}$; CI $-1.23-1.21 \mu \mathrm{mol} / \mathrm{l} ; \quad P=0.98)$, whereas in the patients who started taking hydrochlorothiazide, serum creatinine increased by $5.73 \mu \mathrm{mol} / \mathrm{l}$ (CI 2.82-8.64 $\mu \mathrm{mol} / \mathrm{l}$; $P<0.001)$. The $P$ value for the difference in these trends was less than 0.001 .

\section{Proteinuria in non-diabetic and diabetic patients}

At the time of random allocation to groups, 455 (10.3\%) patients had diabetes mellitus (Table 1) [15]. In comparison with non-diabetic patients $(n=3951)$, diabetic individuals had a greater prevalence of proteinuria at entry to the study (14.5 compared with $8.2 \%$; $P<0.001)$ and a greater calculated creatinine clearance $(66.3 \pm 18.1$ compared with $64.1 \pm 17.0 \mathrm{ml} / \mathrm{min}$ per $\left.1.73 \mathrm{~m}^{2} ; P=0.01\right)$. Serum creatinine at enrolment was similar in diabetic and non-diabetic patients $(88.4 \pm$ 20.3 compared with $88.0 \pm 18.5 \mu \mathrm{mol} / \mathrm{l} ; P=0.64$ ).

The non-diabetic and diabetic patients allocated randomly to the active-treatment group received the study medications in similar proportions (Table 2). Compared with that of patients in the placebo group, their blood pressure also decreased to a similar extent: at the last visit by $11.6 \pm 0.50 \mathrm{mmHg}$ (SE) compared with $10.2 \pm 1.59 \mathrm{mmHg}(P=0.40)$ systolic and by $4.1 \pm 0.2$ compared with $3.1 \pm 0.8 \mathrm{mmHg}(P=0.24)$ diastolic. In the non-diabetic patients there were 52 incident cases of proteinuria in the placebo group and 45 in the active-treatment group. The cumulative rates were 15.1 and 12.1 events per 1000 patient-years $(P=0.26$; Fig. 4). In the diabetic patients, the number of incident cases amounted to 19 and seven in the placebo and active-treatment groups, respectively, and the rates were 58.0 and 18.8 events per 1000 patients-years $(P=0.008)$. Cox regression with adjustment for sex, age, systolic blood pressure at study entry, previous cardiovascular complications and antihypertensive treatment, body mass index, and smoking and alcohol intake at the time of random allocation to groups, confirmed that active treatment reduced the risk of proteinuria significantly more $(P=0.04$; Fig. 3$)$ in the diabetic than in the non-diabetic patients: by $71 \%$ (CI $31-88 \%$ ) compared with $20 \%$ (CI -20 to $46 \%$ ).

\section{Serum creatinine in non-proteinuric and proteinuric patients}

At entry to the study, 390 patients $(8.9 \%)$ had protei-
Fig. 4

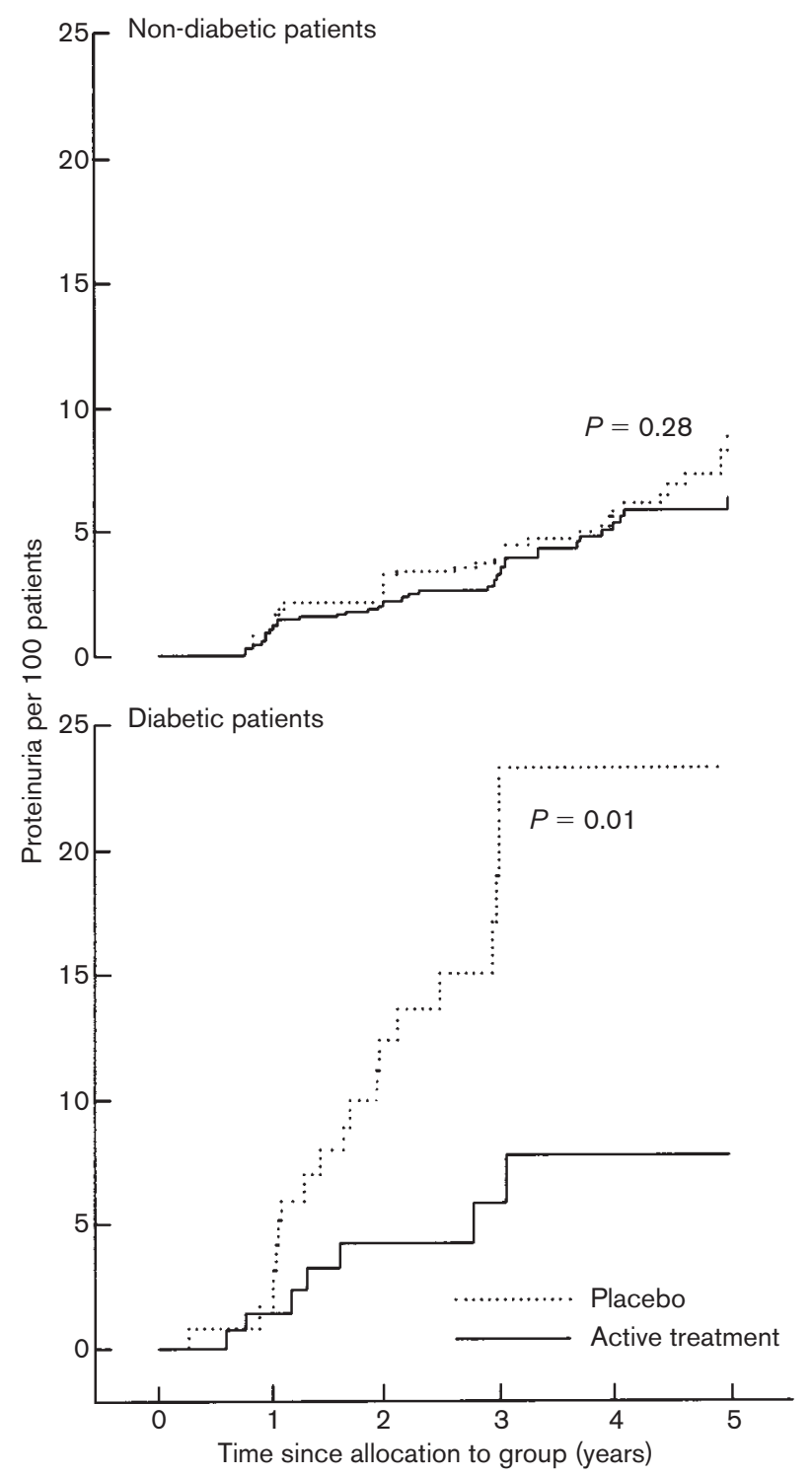

Kaplan-Meier estimates modelling the incidence of proteinuria in nondiabetic and diabetic patients. $P$ values (log-rank test) refer to the difference between placebo and active treatment.

nuria (Table 1). In comparison with the non-proteinuric patients $(n=3983)$, patients with proteinuria had greater serum creatinine concentrations $(91.5 \pm 22.2$ (SD) compared with $87.7 \pm 18.3 \mu \mathrm{mol} / \mathrm{l} ; \quad P=0.001)$ and a lower calculated creatinine clearance $(61.3 \pm 16.9 \mathrm{com}$ pared with $64.7 \pm 17.0 \mathrm{ml} / \mathrm{min}$ per $1.73 \mathrm{~m}^{2} ; P<0.001$ ).

The non-proteinuric and proteinuric patients allocated randomly to the active-treatment group received the study medications in similar proportions, with the exception of the three-drug combination (6.0 compared with $14.0 \% ; P<0.001$; Table 2). Compared with those 
in the placebo group, their blood pressures also decreased to the same extent: at the last visit by $11.4 \pm 0.49$ (SE) compared with $10.8 \pm 1.76 \mathrm{mmHg}$ $(P=0.59)$ systolic and by $4.0 \pm 0.2$ compared with $4.4 \pm 0.8 \mathrm{mmHg} \quad(P=0.57) \quad$ diastolic. Nevertheless, with similar adjustments applied as in Table 3, a significant interaction between the presence of proteinuria at baseline and the effect of active treatment was evident (Fig. 5; $P<0.05$ for all patients and for all cohorts). At median follow-up (2 years), active treatment did not influence serum creatinine concentration in the non-proteinuric patients $(+0.84 \pm 0.55 \mu \mathrm{mol} / \mathrm{l}$; $P=0.13$ ), whereas in those with proteinuria at baseline, the serum creatinine concentration diminished during active treatment $(-6.52 \pm 3.45 \mu \mathrm{mol} / 1 ; P=0.02)$.

\section{Discussion}

We found that, in older patients with isolated systolic hypertension, antihypertensive treatment starting with nitrendipine prevented proteinuria, especially in diabetic patients. Active treatment also prevented mild renal dysfunction and slightly, but significantly, decreased the serum creatinine concentration in patients with proteinuria at entry. In the active-treatment group, serum creatinine did not change in patients who continued to receive nitrendipine monotherapy, but increased if patients took hydrochlorothiazide alone or in combination with other study medication. Serum

\section{Fig. 5}

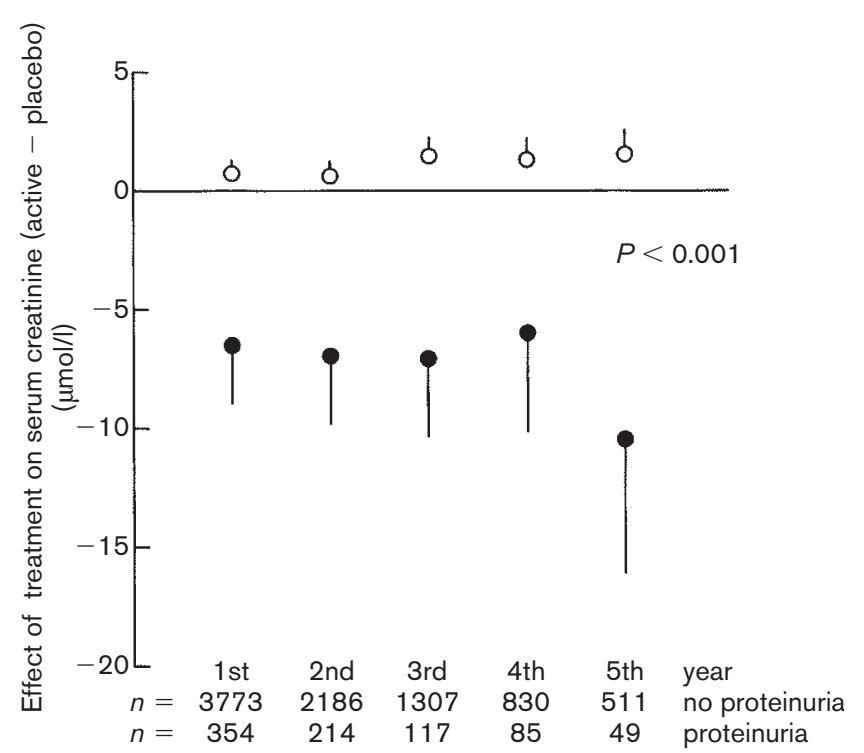

Changes in serum creatinine concentration in proteinuric and nonproteinuric patients by year of follow-up. The differences between placebo and active treatment were adjusted for the same factors as in Table 3. The interaction between the presence of proteinuria at baseline and active treatment was significant $(P<0.001)$. creatinine, the calculated creatinine clearance [20] and proteinuria are only intermediary outcome measures, but they are positively associated with an increased cardiovascular risk and greater mortality $[25,26]$.

The findings of the National Intervention Cooperative Study in Elderly Hypertensives [7] are in keeping with our own. Older (at least 60 years) hypertensive patients were assigned randomly to receive double-blind treatment with $20 \mathrm{mg}$ sustained-release nicardipine twice daily $(n=204)$ or $2 \mathrm{mg}$ trichlormethiazide once daily $(n=210)$. The untreated blood pressure at study entry was 172/94 mmHg. Over 4.3 years of follow-up, cardiovascular morbidity was similar in both treatment groups [7]. Blood urea nitrogen increased by $0.35 \mathrm{mmol} / \mathrm{l}$ in the nicardipine group and by $1.14 \mathrm{mmol} / \mathrm{l}$ in those receiving diuretic treatment $(P=0.07$ for betweengroup difference). Significantly fewer patients in the nicardipine group attained abnormally increased (at least $21.4 \mathrm{mmol} / \mathrm{l}$ ) blood urea nitrogen concentrations (2.6 compared with $7.6 \% ; P=0.03$ ).

In the Appropriate Blood Pressure Control in Diabetes (ABCD) trial [12], the mean blood pressures achieved were $132 / 78 \mathrm{mmHg}$ and $136 / 86 \mathrm{mmHg}$ in the intensive and moderate treatment groups, respectively. During the 5-year follow-up period, no difference was observed between intensive and moderate blood pressure control and between patients allocated randomly to nisoldipine or enalapril groups with regard to the change in creatinine clearance. Intensive compared with moderate treatment did not influence the progression from normo-albuminuria to proteinuria, but reduced the overall incidence of mortality [12]. In the patients assigned randomly to receive enalapril compared with nisoldipine, the initial reduction in the urinary albumine excretion was not sustained beyond 3.5 years of followup [12]. The Ramipril Efficacy in Nephropathy study included 117 non-diabetic patients with chronic proteinuric nephropathies, allocated randomly to receive angiotensin converting enzyme inhibition or placebo plus conventional antihypertensive therapy [11]. The authors reported that dihydropyridine calcium-channel blockers had an adverse effect on renal protein excretion, which was minimized by ramipril and tight blood pressure control [11]. However, bias of indication was an important confounder in the post-hoc analysis of this small study, because calcium-channel blockers were only used in an open-label non-randomized fashion as the third-line medication in patients with treatmentresistant hypertension. As in our study, other investigators found that nitrendipine reduced proteinuria in type-1 and type-2 diabetes mellitus [27] - an effect similar to the well-known antiproteinuric action of angiotensin converting enzyme inhibitors [28]. Furthermore, nitrendipine given to renal transplant patients treated with cyclosporin had a renoprotective effect, 
which was independent of the antihypertensive action of the drug [29].

In the double-blind placebo-controlled trial conducted by the European Working Party on High Blood Pressure in the Elderly $[2,8,30]$, the patients of the activetreatment group received hydrochlorothiazide plus triamterene, to which, in $35 \%$ of the patients, $\alpha$ methyldopa was added [2,8,30]. During follow-up, serum creatinine concentration increased in both treatment groups, but the increase was already more pronounced in the actively treated group after 3 months $(15.9 \mu \mathrm{mol} / \mathrm{l} ;$ compared with $1.8 \mu \mathrm{mol} / \mathrm{l} ; \quad P<0.001)$ [2,8,30]. With incidence rates of 33.3 and 9.8 events per 1000 patient-years, the risk of mild renal dysfunction (serum creatinine concentration at least $180 \mu \mathrm{mol} / \mathrm{l}$ ) was $23 \%$ greater (CI 12-35\%) in actively treated patients [8]. Thiazides, $\beta$-blockers, or their combination, constituted the mainstay of active treatment in the Hypertension in Elderly Patients in Primary Care trial (HEP) [4], in the Swedish Trial in Old Patients with Hypertension (STOP) [5], and in the Systolic Hypertension in the Elderly Program (SHEP). Significant increases in serum creatinine concentration were observed in the HEP [4] and STOP [5] trials (5 and $10 \mathrm{mmol} / \mathrm{l}$, respectively). In the SHEP trial [6], after 3 years of follow-up, serum creatinine concentration had not significantly changed in the placebo group $(+0.5 \mu \mathrm{mol} / \mathrm{l}$; $P=0.31)$, but had increased by $3.3 \mu \mathrm{mol} / \mathrm{l}(P<0.001)$ in the patients assigned randomly to receive active treatment $(P<0.001$ for between-group difference). However, after 3 years, the incidence of mild renal dysfunction (serum creatinine at least $176.8 \mu \mathrm{mol} / \mathrm{l}$ ) was similar in the placebo and active-treatment group, regardless of the absence (1.2 compared with $1.2 \%$ ) or presence (2.9 compared with $1.8 \%$ ) of diabetes mellitus at study entry [6].

Our findings, combined with the evidence from other intervention trials $[4-6,12,27,29,30]$, raise the possibility that antihypertensive treatment with long-acting dihydropyridines may offer specific renoprotection over and beyond their blood pressure-decreasing effect, and that this class of drug may protect renal function better than do the thiazides. Diuretics increase serum creatinine in a dose-dependent way [31] and decrease the glomerular filtration rate, probably because the contracted extracellular fluid volume and the decreasing of cardiac output diminish glomerular capillary plasma flow [32,33]. Most calcium-channel blockers preferentially dilate the afferent arteriole and, theoretically, their renal microcirculatory effects might not favour an attenuation of glomerular hypertension [17]. However, there are possible mechanisms other than the reduction of intraglomerular capillary pressure whereby calcium channel blockers could prevent renal dysfunction - for example, the attenuation of the mitogenic effects of growth factors [34], the modulation of macromolecular traffic across and entrapment within the mesangium, the inhibition of the renal effects of endothelin, and the decrease in free radical formation [17].

\section{Study limitations}

The present study must be interpreted within the context of its limitations. The creatinine clearance was calculated instead of measured, and proteinuria was determined in a semiquantitative fashion. The comparison of renal function between active treatment and placebo followed the double-blind and randomized design of the trial, but the subgroup analyses according to the presence or absence of diabetes mellitus or proteinuria at study entry or according to the use of study medications in the active-treatment group are not necessarily free of bias, although we accounted for known confounders. As expected in ageing patients, we found, with longer follow-up, a small decrease in the calculated creatinine clearance. This was not accompanied by an increase in the serum creatinine concentration, probably because, with senescence, lean body weight also decreased. The decrease in the calculated creatinine clearance with longer follow-up was not an artefact caused by the negative age-term in Cockroft and Gault's formula [20]. Indeed, the $P$ values for time since random allocation to groups, and the treatmentby-time interaction terms did not materially change if actual age at each time point was replaced by age at baseline.

\section{Conclusion}

In spite of their limitations, the present findings suggest that antihypertensive treatment based on longacting dihydropyridine calcium channel blockers may protect renal function, especially in patients with diabetes mellitus or pre-existing proteinuria.

\section{Acknowledgements}

The Syst-Eur Trial was a concerted action of the Biomedicine and Health (BIOMED) Research Program sponsored by the European Union. The trial was carried out in consultation with the World Health Organization, the International Society of Hypertension, the European Society of Hypertension and the World Hypertension League. Professor M. Epstein (University of Miami Medical School, Miami, Florida, USA) provided helpful comments on the manuscript.

\section{References}

1 Freedman BI, Iskandar SS, Appel RG. The link between hypertension and nephrosclerosis. Am J Kidney Dis 1995; 25-I:207-221.

2 de Leeuw PW. Renal function in the elderly: results from the European Working Party on High Blood Pressure in the Elderly Trial. Am J Med 1991; 90 (suppl 3A):45S-49S.

3 Staessen J, Amery A, Fagard R. Editorial review. Isolated systolic hypertension in the elderly. J Hypertens 1990; 8:393-405.

4 Coope J, Warrender TS. Randomised trial of treatment of hypertension in elderly patients in primary care. BMJ 1986; 293:1145-1151. 
5 Ekbom T, Dahlöf B, Hansson L, Lindholm LH, Scherstén B, Wester PO. Antihypertensive efficacy and side effects of three beta-blockers and a diuretic in elderly hypertensives: a report from the STOP-Hypertension study. J Hypertens 1992; 10:1525-1530.

6 Savage PJ, Pressel SL, Curb JD, Schron EB, Applegate WB, Black HR, et al. Influence of long-term low-dose diuretic-based antihypertensive therapy on glucose, lipid, uric acid, and potassium levels in older men and women with isolated systolic hypertension. The Systolic Hypertension in the Elderly Program. Arch Intern Med 1999; 158:741-751.

7 National Intervention Cooperative Study in Elderly Hypertensives Study Group. Randomized double-blind comparison of a calcium antagonist and a diuretic in elderly hypertensives. Hypertension 1999; 34:1129-1133.

8 Fletcher A, Amery A, Birkenhäger W, Bulpitt C, Clement D, de Leeuw P, et al. Risks and benefits in the trial of the European Working Party on High Blood Pressure in the Elderly. J Hypertens 1991; 9:225-230.

9 Epstein M. Calcium antagonists and renal disease. Kidney Int 1998; 54:1771-1784.

10 Kloke HJ, Branten AJ, Huysmans FT, Wetzels JF. Antihypertensive treatment of patients with proteinuric renal disease: risks or benefits of calcium channel blockers? Kidney Int 1998; 53:1559-1573.

11 Ruggenenti P, Perna A, Benini R, Remuzzi G, for the 'Gruppo Italiano di Studi Epidemiologici in Nefrologia' (GISEN). Effects of dihydropyridine calcium channel blockers, angiotensin-converting enzyme inhibition, and blood pressure control on chronic, nondiabetic nephropathies. J Am Soc Nephrol 1998; 9:2096-2101.

12 Estacio RO, Gifford N, Jeffers BW, Schrier RW. Effects of blood pressure control on diabetic microvascular complications in patients with hypertension and type 2 diabetes. Diabet Care 2000; 23 (suppl 2):B54-B64.

13 Staessen JA, Fagard R, Thijs L, Celis H, Arabidze GG, Birkenhäger WH, et al. Randomised double-blind comparison of placebo and active treatment for older patients with isolated systolic hypertension [erratum published in Lancet 1997; 350:1636]. Lancet 1997; 350:757-764.

14 Staessen JA, Fagard R, Thijs L, Celis H, Birkenhäger WH, Bulpitt CJ, et al. Subgroup and per-protocol analysis of the randomized European trial on isolated systolic hypertension in the elderly. Arch Intern Med 1998; 158:1681-1691.

15 Tuomilehto J, Rastenyte D, Birkenhäger WH, Thijs L, Antikainen R, Bulpitt $\mathrm{CJ}$, et al. Effects of calcium-channel blockade in older patients with diabetes and systolic hypertension. N Engl J Med 1999; 340:677-684.

16 Goa KL, Sorkin EM. Nitrendipine. A review of its pharmacodynamic and pharmacokinetic properties and therapeutic efficacy in the treatment of hypertension. Drugs 1987; 33:123-155.

17 Epstein M. Calcium antagonists and renal protection: emerging perspectives. J Hypertens 1998; 16 (suppl 4):S17-S25.

18 Griffin KA, Picken MM, Bakris GL, Bidani AK. Class differences in the effects of calcium channel blockers in the rat remnant kidney model. Kidney Int 1999; 55:1849-1860.

19 Gehan EA, George SL. Estimation of human body surface area from height and weight. Cancer Chemother Rep 1970; 54:225-235.

20 Cockcroft DW, Gault MH. Prediction of creatinine clearance from serum creatinine. Nephron 1976; 16:31-41.

21 Kvist $\mathrm{H}$, Chowdhury B, Grangård U, Tylén U, Sjöström L. Total and visceral adipose-tissue volumes derived from measurements with computed tomography in adult men and women: predictive equations. Am J Clin Nutr 1988; 48:1351-1361.

22 Report of a WHO Study Group. Prevention of diabetes mellitus. Geneva, Switzerland: World Health Organization; 1994.

23 Kleinbaum DG, Kupper LL, Muller KE. Dummy variables in regression. In: Applied regression analysis and other multivariate methods. 2nd ed. Boston, Massachusetts: PWS-Kent Publishing Company; 1988. pp. 260-296.

24 Sokolow M, Lyon TP. The ventricular complex in left ventricular hypertrophy as obtained by unipolar precordial and limb leads. Am Heart $J$ 1949; 37:161-186.

25 Damsgaard EM, Froland A, Jorgensen OD, Mogensen CE. Microalbuminuria as predictor of increased mortality in elderly people. BMJ 1990; 300:297300.

26 Shulman NB, Ford CE, Hall WD, Blaufox MD, Simon D, Langford HG, Schneider KA, on behalf of the Hypertension Detection and Follow-up Program Cooperative Group. Prognostic significance of serum creatinine and effect of treatment of hypertension on renal function. Results from the Hypertension Detection and Follow-up Program. Hypertension 1989; 13 (suppl I):I-80-I-93.

27 Bretzel RG, Bollen CC, Maeser E, Federlin KF. Nephroprotective effects of nitrendipine in hypertensive type I and type II diabetic patients. Am J Kidney Dis 1993; 21 (suppl 3):53-64.

28 Mosconi L, Ruggenenti P, Perna A, Mecca G, Remuzzi G. Nitrendipine and enalapril improve albuminuria and glomerular filtration rate in non-insulin dependent diabetes. Kidney Int 1996; 49 (suppl 55):S91-S93.

29 Rahn KH, Barenbrock M, Fritschka E, Heinecke A, Lippert J, Schroeder K, et al. Effect of nitrendipine on renal function in renal-transplant patients treated with cyclosporin: a randomised trial. Lancet 1999; 354: $1415-1420$.

30 Amery A, Berthaux P, Birkenhäger W, Boel A, Brixko P, Bulpitt C, et al. Antihypertensive therapy in patients above age 60 years (Fourth Interim Report of the European Working Party on High Blood Pressure in Elderly: EWPHE). Clin Sci Mol Med 1978; 55:263S-270S.

31 Carlsen JE, Køber L, Torp-Pedersen C, Johansen P. Relation between dose of bendrofluazide, antihypertensive effect, and adverse biochemical effects. Br Med J 1990; 300:975-978.

32 Brenner BM, Troy JL, Daugharty TM, Deen WN, Robertson CR. Dynamics of glomerular ultrafiltration in the rat: II. Plasma flow dependence of GFR. Am J Physiol 1972; 223:1184-1190.

33 Seely JF, Dirks JH. Site of action of diuretic drugs. Kidney Int 1977; 11: $1-8$.

34 Schultz P, Raij L. Inhibition of human mesangial cell proliferation by calcium channel blockers. Hypertension 1990; 15 (suppl 1):76-80.

\section{Appendix: Syst-Eur investigators}

Trial coordinators: Robert Fagard; Jan A. Staessen.

Regional coordinators: Guramy G. Arabidze (Bellorussia and the Russian Federation); Willem H. Birkenhäger (The Netherlands); Christopher J. Bulpitt (UK); Manuel Carrageta (Portugal); Hilde Celis (Belgium); Françoise Forette (France); Jozef Kocemba (Poland); Gastone Leonetti (Italy); Choudomir Nachev (Bulgaria); Eoin T. O'Brien (Ireland); Eberhard Ritz (Germany); José L. Rodicio (Spain); Joseph Rosenfeld (Israel); Jaakko Tuomilehto (Finland, Estonia and Lithuania).

Steering committee: Guramy G. Arabidze; Paul De Cort; Robert Fagard; Françoise Forette; Kalina Kawecka-Jaszcz; Gastone Leonetti; Choudomir Nachev; Eoin T. O’Brien; José L. Rodico; Joseph Rosenfeld; Jaakko Tuomilehto; John Webster; Yair Yodfat.

Data monitoring committee: Christopher J. Bulpitt; Astrid E. Fletcher; Jan A. Staessen; Lutgarde Thijs.

Endpoint committee: Robert Fagard; Peter W. de Leeuw; Gastone Leonetti; James C. Petrie.

Ethics committee: Willem H. Birkenhäger; Colin T. Dollery; Robert Fagard.

Publication committee: Willem H. Birkenhäger; Christopher J. Bulpitt; Jan A. Staessen; Alberto Zanchetti.

Clinical centres: The clinical investigators are listed by Staessen et al. [13,14]. 